\title{
Biophysical characterization of antibacterial compounds derived from pathogenic fungi Ganoderma boninense ${ }^{\S}$
}

\author{
Syahriel Abdullah ${ }^{1 \dagger}$, Yoon $\mathrm{Sin} \mathrm{Oh}^{2 \dagger}$, \\ Min-Kyu Kwak ${ }^{2 \star}$, and KhimPhin Chong ${ }^{1 \star}$ \\ ${ }^{1}$ Faculty of Science and Natural Resources, Universiti Malaysia Sabah, \\ Jalan UMS, 88400, Kota Kinabalu, Sabah, Malaysia \\ ${ }^{2}$ Department of Food and Nutrition, Institute of Food and Nutrition \\ Science, Eulji University, Seongnam 13135, Republic of Korea \\ (Received Oct 28, 2020 / Revised Nov 10, 2020 / Accepted Nov 10, 2020)
}

There have been relatively few studies which support a link between Ganoderma boninense, a phytopathogenic fungus that is particularly cytotoxic and pathogenic to plant tissues and roots, and antimicrobial compounds. We previously observed that liquid-liquid extraction (LLE) using chloroformmethanol-water at a ratio (1:1:1) was superior at detecting antibacterial activities and significant quantities of antibacterial compounds. Herein, we demonstrate that antibacterial secondary metabolites are produced from $G$. boninense mycelia. Antibacterial compounds were monitored in concurrent biochemical and biophysical experiments. The combined methods included high performance thin-layer chromatography (HPTLC), gas chromatography-mass spectrometry (GC-MS), high-performance liquid chromatography (HPLC), fourier transform infrared (FTIR), and nuclear magnetic resonance (NMR) spectroscopy. The antibacterial compounds derived from mycelia with chloroform-methanol extraction through LLE were isolated via a gradient solvent elution system using HPTLC. The antibacterial activity of the isolated compounds was observed to be the most potent against Staphylococcus aureus ATCC 25923 and multidrug-resistant $S$. aureus NCTC 11939. GC-MS, HPLC, and FTIR analysis confirmed two antibacterial compounds, which were identified as 4,4,14a-trimethylcholestane $(\mathrm{m} / \mathrm{z}=414.75$; lanostane, $\left.\mathrm{C}_{30} \mathrm{H}_{54}\right)$ and ergosta-5,7,22-trien- $3 \beta$-ol $(\mathrm{m} / \mathrm{z}=396.65$; ergosterol, $\mathrm{C}_{28} \mathrm{H}_{44} \mathrm{O}$ ). With the aid of spectroscopic evaluations, ganoboninketal $\left(\mathrm{m} / \mathrm{z}=498.66, \mathrm{C}_{30} \mathrm{H}_{42} \mathrm{O}_{6}\right)$, which belongs to the 3,4-seco-27-norlanostane triterpene family, was additionally characterized by 2D-NMR analysis. Despite the lack of antibacterial potential exhibited by lanostane; both ergosterol and ganoboninketal displayed significant antibacterial activities against bacterial pathogens. Results provide evidence for the existence of bioactive compounds in the mycelia of

\footnotetext{
${ }^{\dagger}$ These authors contributed equally to this work.

*For correspondence. (M.K. Kwak) E-mail: genie6@eulji.ac.kr; Tel.: +8231-740-7418; Fax: +82-31-740-7370 / (K.P. Chong) E-mail: chongkp@ums. edu.my; Tel.: +60-88-320-000; Fax: +60-88-435-324

${ }^{5}$ Supplemental material for this article may be found at

http://www.springerlink.com/content/120956.

Copyright (c) 2021, The Microbiological Society of Korea
}

the relatively unexplored phytopathogenic G. boninense, together with a robust method for estimating the corresponding potent antibacterial secondary metabolites.

Keywords: antibacterial activity, disc diffusion assay, ergosterol, ganoboninketal, Ganoderma boninense, lanostane

\section{Introduction}

The intricate cross-talk between the bioactive phytochemicals and antimicrobial constituents of certain basidiomycetes has recently been highlighted, but their significance has not yet been evaluated (Schwan, 2012). Some of basidiomycetes have attracted considerable attention owing to the widespread increase in the prevalence of natural and nosocomial infections, along with antibiotic resistance. As a major class of higher fungi, they can adapt to environmental conditions, and as mushrooms, they potentially possess excellent immunomodulatory functions (Anke, 1989; Ma et al., 2014). Specifically, many species from the genus Ganoderma of the Ganodermataceae family have been steadily suggested to exhibit antimicrobial activities by the presence of bioactive compounds, such as triterpenoids, colossolactones, and polysaccharides (Ofodile et al., 2012). Ganoderma boninense, also known as bracket fungi, belongs to the genus of polypore fungi Ganoderma of the Ganodermataceae (Polyporales) family (Peng et al., 2014; Richter et al., 2015). Meanwhile, there remains undiscovered potential for bioactivity and functionality in G. boninense. This is because this phytopathogenic G. boninense is recognized as the most virulent and predominant cause of basal stem rot (Ho and Nawawi, 1985), which is one of the most restrained diseases affecting the oil palm industry (Corley et al., 2008). Thus, due to its notorious reputation, G. boninense has yet to have its medicinal potential sufficiently clarified.

The sole evidence of most observed bioactive secondary metabolites is predominantly restricted to lanostane-type triterpenoids and their derivatives in G. boninense (Gong et al., 2019). Thus, there is limited information regarding G. boninense metabolites such as 3,4-seco-27-norlanostane triterpenes. Lanostanes from $G$. boninense commonly include 3 ganoboninketals and 6 ganoboninones with a tetradecahydrobenzo[4,5]indeno[1,7a-c]furan backbone (Ma et al., 2014, 2015). To a greater or lesser degree, these compounds derived from $G$. boninense exhibit antimicrobial activities, such as anti-Candida (Daruliza et al., 2012), anti-plasmodial (Ma et al., 2015), and antibacterial activity (Ismail et al., 2014). However, most studies on $G$. boninense excessively emphasize its pathogenicity and its consequent negative effects on oil palm 
(Chong et al., 2011, 2012, 2013), rather than exploring its medicinal potential. For this reason, convincing experimental evidence on the biologically active secondary metabolites of G. boninense is still lacking.

Despite substantial developments in aspects of extraction and separation techniques in the case of drug discovery studies, isolation of natural products is still an exceptionally challenging process. Undoubtedly, comprehensive structural verification data regarding the metabolites of novel drugs and/or biologically active secondary metabolites have been developed via hybrid methods such as gas chromatography-mass spectrometry (GC-MS), liquid chromatography-mass spectrometry (LC-MS), two-dimensional nuclear magnetic resonance spectroscopy (2D-NMR), or interfacing liquid chromatography with parallel NMR and mass spectrometry (LC-NMRMS) (Schlotterbeck and Ceccarelli, 2009; Sarker and Nahar, 2012). These biophysical approaches enable scientific and commercial applications in natural products, combinatorial chemistry, and drug metabolism studies. Full chemical structures, including the stereochemistry of new compounds, most likely need to be isolated, as this data requires highly purified compounds. For example, 2D-NMR spectra of small molecules can be obtained with less than $100 \mu \mathrm{g}$ (Molinski, 2010; Mahrous and Farag, 2015). Furthermore, in vitro and in vivo bioassays required for evaluating biological activities have been performed, followed by a purification process to exclude interference and impurities (Bucar et al., 2013). Finally, reference standards for the quality control of natural product medicines largely depend on isolated compounds with documented purity. In recent years, natural products have experienced a renaissance in drug discovery programs, mainly due to their drug-like properties and their superior chemical diversity over synthetic compound libraries (Vetter et al., 2011).

In the present study, we demonstrated and evaluated techniques for the isolation, identification, and characterization of antibacterial compounds derived from G. boninense mycelia. We have previously evaluated the efficacy of liquidliquid extraction (LLE) for the isolation of potential antibacterial compounds (Abdullaha et al., 2020). To detect and isolate these antibacterial compounds, we employed biochemical methods, including high performance thin-layer chromatography (HPTLC), GC-MS, infrared (IR), and 2D-NMR spectroscopy. The revealed antibacterial compounds were respectively tested against pathogenic Gram-positive and Gramnegative bacteria. Our findings propose the employment of a new, more robust method for estimating the potent antibacterial secondary metabolites in the mycelia of G. boninense, a relatively unexplored phytopathogenic fungal strain.

\section{Materials and Methods}

\section{Strains and culture conditions}

All fungal and bacterial strains used in this study are listed in Supplementary data Table S1. Mycelia and fruiting bodies were obtained from oil palm (Elaeis guineensis Jacq.) infected by $G$. boninense, with the infection scores of the selected palm trees being assessed according to the disease severity index of G. boninense-infected oil palms (Chong et al., 2014). Ganoderma boninense collection was conducted at Langkon
Plantation, Sawit Kinabalu, Sabah, Malaysia. Based on our previous experiments regarding the relatively higher antibacterial properties of $G$. boninense mycelia (Abdullaha et al., 2020), G. boninense mycelium cultured on potato dextrose agar (PDA), designated as GBMA, was used in this study.

Ganoderma boninense was cultured to obtain mycelia as previously described, with modifications (Abdullah et al., 2018). Ganoderma boninense mycelia were inoculated on PDA plates and were routinely cultured at $28^{\circ} \mathrm{C}$ for 14 days. The resulting mycelial plugs were transferred to PDA and PDB plates and were cultured for further experimentation. Mycelial plugs were loaded onto PDA agar media and were again cultured for 7 days at $28^{\circ} \mathrm{C}$. Additionally, five mycelial plugs were inoculated into PDB liquid medium and were cultured for 7 days at $28^{\circ} \mathrm{C}$. Unless otherwise stated, each strain for the biochemical experiments was routinely cultured in nutrient broth (NB) (Merck) at $37^{\circ} \mathrm{C}$. The grown mycelia and/or fruiting bodies were harvested via centrifugation at $10,000 \times g$ for 5 min, washed with $200 \mathrm{mM}$ phosphate-buffered saline (PBS); $\mathrm{pH} 7.0$, and resuspended in $1 \mathrm{ml} 30 \%$ glycerol solution.

Six bacterial strains were used for the antibacterial activity assays. Gram-positive bacteria, including S. aureus American Type Culture Collection (ATCC 25923), multidrug-resistant S. aureus (MRSA) National Collection of Type Culture (NCTC 11939), and S. pyogenes ATCC 19615, were used. In contrast, $P$. aeruginosa ATCC 9027, K. pneumoniae ATCC 1705, and E. coli ATCC 35218 were used as Gram-negative bacteria. ATCC bacterial strains and MRSA (NCTC 11939) were purchased from Sigma-Aldrich or Oxoid Ltd., respectively. Prior to antibacterial activity assays using solvent-extracted G. boninense, the exponential phase of the growth cycle of all bacterial strains was determined as previously described (Brannan, 2006).

\section{Preparative high-performance thin layer chromatography (pHPTLC)}

To isolate unknown compounds, thin-layer chromatography (TLC) was utilized as previously reported (Rajauria and AbuGhannam, 2013). A high-performance thin-layer chromatography (HPTLC) system (CAMAG) equipped with a sample applicator was used for compound purification. Approximately $100 \mu \mathrm{l}$ of the CM and WM fractions was used for the band spraying application, with three replicates on each $10 \mathrm{~cm}$ $\times 10 \mathrm{~cm}$ preparative-TLC (PTLC) glass silica gel plate (Merck, Gel 60, $1 \mathrm{~mm}$ thick) in the stationary phase. The combination of PTLC and HPTLC was used to prepare the biological samples and for their separation. PTLC plates were developed in a twin trough glass separation chamber using a gradient solvent separation system, as summarized in Supplementary data Table S2.

The bands derived from the CM and WM fractions on the PTLC plates were visualized under visible (white), short UV (254 nm), and long UV (366 nm) lights using a visualizer (CAMAG Visualizer). The movement of each separated band from the two fractions was expressed as its retention factor (Rf). pHPTLC separation of the CM fraction was performed with 68 plate replicates. Thereafter, 18 plates were used for the pHPTLC antibacterial bioassay on the six bacterial samples whereas the other 50 plates were used for antibacterial compound isolation. 


\section{pHPTLC antibacterial bioautography evaluation}

The pHPTLC antibacterial bioassay protocol was adopted as proposed previously (Valle et al., 2016), with minor modifications. Six bacterial strains grown until the exponential phase were harvested, washed, resuspended, and adjusted with NB until 2-4.5 $\times 10^{5}(\mathrm{CFU} / \mathrm{ml})$ was reached, according to the guidelines of the CLSI (CLSI, 2011). Approximately $1 \mathrm{ml}$ of each bacterial sample was inoculated and was mixed into $30 \mathrm{ml}$ of nutrient agar (NA), and this was then poured onto a PTLC plate containing both fractions.

\section{GC-MS analysis}

GC-MS analysis of the potential antibacterial compounds was performed as previously described (Ma et al., 2014), with minor modifications. The separated bands that exhibited antibacterial potential $(\mathrm{Rf}=0.4)$ were collected, transferred into a $15 \mathrm{ml}$ polytetrafluoroethylene (PTFE) centrifuge tube, to which $3 \mathrm{ml}$ of methanol:chloroform (1:1) was added. This was vortexed and centrifuged at 5,000 rpm for $5 \mathrm{~min}$ to separate the antibacterial compounds from PTLC silica gel. For GC-MS analysis, the isolated compounds were diluted to $200 \mathrm{ppm}$, filtered with a $0.45 \mu \mathrm{m}$ PTFE filter, and then transferred into a $2 \mathrm{ml}$ borosilicate amber glass (Agilent Technologies). GC-MS analysis of the isolated compounds was performed using an Agilent 2000 Electron Spray ionization GCMS equipped with a fused silica $15 \mathrm{~m} \times 0.2 \mathrm{~mm} \mathrm{ID} \times 1 \mu \mathrm{m}$ capillary column. The ionization voltage was $70 \mathrm{eV}$. The raw data obtained from the GC-MS were converted into vendorindependent network common data format (NetCDF) format. MZmine software version 2.23 (http://mzmine.github.io) was used for data processing. Agilent MassHunter software with the Find Molecular Formula Algorithm function (MFG) was also used for molecular formula prediction based on mass fragmentation. For identification, the NIST MS Search- v.2.3 (2017) software with NIST 17 EI Library Version was utilized.

\section{Semi-preparative high-performance liquid chromatography} (sPHPLC) analysis of the isolated compounds from pHPTLC

Prior to sPHPLC analysis, lyophilized compounds from pHPTLC were dissolved in $100 \mathrm{mg} / \mathrm{ml}$ acetonitrile. sPHPLC separation was performed as previously described (Ma et al., 2014) with some modifications. A Shimadzu LC-6AD HPLC system was used for analysis, with an injection volume of 5 $\mathrm{ml}$ using a preparative reverse phase (RP) Shim-pack PRCODS $(250 \times 20 \mathrm{~mm}$ id, $5 \mu \mathrm{m}$, Shimadzu) with a wavelength of $282 \mathrm{~nm}$. The mobile phase consisted of acetonitrile (A) and $0.1 \%$ TFA in water (B) using a gradient elution of $15-40 \%$ $\mathrm{A}$ at $0-10 \mathrm{~min}, 40-60 \% \mathrm{~A}$ at $10-25 \mathrm{~min}, 60-100 \% \mathrm{~A}$ at $25-45$ min, and $100 \% \mathrm{~A}$ at $45-55 \mathrm{~min}$. The flow rate was maintained at $3 \mathrm{ml} / \mathrm{min}$. A Shimadzu FRC-10A Fraction Collector was utilized to collect specific compounds at specific sPHPLC retention times (Rt). Compounds identified earlier using GCMS were spiked with standards to confirm the identity of the isolated compounds. The ample fraction was collected through a series of sPHPLC and was freeze-dried for further experimental use.
Fourier transform infrared (FTIR) spectroscopy analysis on compounds fractionated from sPHPLC

The FTIR spectra of the isolated compounds from sPHPLC were acquired at room temperature using a Perkin Elmer 1600 FTIR spectrometer. The sampling station was equipped with an overhead attenuated total reflection accessory (ATR) comprising transfer optics within the chamber through which infrared radiation was directed to a detachable zinc selenide crystal mounted into a shallow trough for sample containment. The crystal geometry was a $45^{\circ}$ parallelogram with mirrored angled faces, with 10 nominal internal reflections. Approximately 64 scans were co-added at a nominal resolution of $4 / \mathrm{cm}$ in the spectral region of $4,000-650 / \mathrm{cm}$. Singlebeam spectra of the samples were collected and rationed against the background and presented as absorbance units. Samples were applied to the ATR crystal to obtain the total crystal coverage; the crystal was cleaned between samples using acetone and dried with a lens cleaning tissue. The cleaned crystal was carefully examined visually to ensure that no residue from the previous sampling was retained on the crystal surface and was checked with the background spectrum. FTIR spectra for known compounds based on MS analysis were cross-referenced with their respective standard for further identity confirmation.

\section{NMR spectroscopy analysis of a new potential antibacterial compound isolated from $G$. boninense}

NMR spectral studies for 2D-NMR analysis on compound $\mathrm{C}$ were performed at the Analytical Biochemistry Research Centre (ABrC), Universiti Sains Malaysia using an NMR $700 \mathrm{MHz}$ ASCEND ${ }^{\mathrm{TM}}$ spectrometer. Heteronuclear multiple-bond correlation spectroscopy (HMBC), heteronuclear single quantum coherence spectroscopy (HSQC), NMR correlation spectroscopy (COSY), nuclear Overhauser effect spectroscopy (NOESY), and UV circular dichroism (CD) for both experimental and calculated Electronic Circular Dichroism (ECD), as well as in silico structural analysis using Merck Molecular Force Field (MMFF94 variant using Conflex calculation), were subsequently performed for the elucidation of the $\mathrm{ABrC}$ compound structure.

\section{Antibacterial evaluation of identified compounds against the bacterial samples}

The antibacterial activities of the identified compounds were evaluated using a disc diffusion assay as guided by CLSI (CLSI, 2011). Each compound was prepared at $1 \mathrm{mg} / \mathrm{ml}$ in $10 \%$ DMSO to create the stock solution. Approximately 100 $\mu \mathrm{l}(100 \mu \mathrm{g}, 1 \mu \mathrm{g} / \mu \mathrm{l}$ of concentration) of each compound was loaded into their respective discs. For the negative control discs, $10 \%$ DMSO was loaded in order to separate the discs. Chloramphenicol $(30 \mu \mathrm{g})$ was used as the positive control. Media and bacterial preparation for the antibacterial bioassay was performed according to methods previously described (Abdullaha et al., 2020). The plates were then incubated at $37^{\circ} \mathrm{C}$ for $12-48 \mathrm{~h}$ in an incubator, and the antibacterial activity of the identified compounds was determined by measuring the size of the inhibition zone $(\mathrm{mm})$. 


\section{Antibacterial activity assays}

A comparative antibacterial experiment was performed using various culture media, namely, tryptic soy agar (TSA), Muller-Hinton agar, NA, and Luria-Bertani agar (LBA). Bacterial cultures were incubated at $37^{\circ} \mathrm{C}$ until the exponential growth phase. Antibacterial activity was observed using conventional disc diffusion assay, as illustrated in CLSI guidelines (CLSI, 2011).

Approximately $0.1 \mathrm{ml}$ of bacterial culture was adjusted to $1 \times 10^{8} \mathrm{CFU} / \mathrm{ml}$ prior to inoculation onto nutrient agar plates. Sterilized Whatman ${ }^{\circledR}$ No. 3 paper (6 mm diameter discs) was used for the assay. Before loading $50 \mu \mathrm{l}(5 \mathrm{mg})$ of the Ganoderma extracts, the concentration of each extract sample was set to $100 \mathrm{mg} / \mathrm{ml}$. All lyophilized extracts of the Ganoderma samples were dissolved in $10 \%$ DMSO by dilution with tripledistilled water, except for the water-extracted samples.

For the positive control experiment, $50 \mu \mathrm{l}$ of $10 \%$ DMSO was added to the discs and supplemented with tetracycline, chloramphenicol, or ampicillin; chloroform was used as the negative control. The diameter of the zone of inhibition ( $\mathrm{mm}$ ) around the disc was measured after cultivation as described above and was compared with the control.

\section{Statistical analysis}

Data are expressed as the mean \pm standard deviation (SD) of at least three independent experiments. The statistical significance of the differences was preliminarily evaluated using the Student's t-test in Microsoft Office Excel 2016. To evaluate the statistical significance of the experimental parameters, data were compared using one-way analysis of variance, followed by post-hoc tests such as Tukey's test, Duncan's multiple range test, and least significance difference. The level of significance was set at $p=0.05$, and statistical analyses were performed using SPSS software, ver. 21 (SPSS Inc.).

\section{Results and Discussion}

\section{pHPTLC profiles and corresponding antibacterial bioauto- graphy of the CM based on extraction yield using LLE}

We have previously evaluated three culture type-dependent G. boninense, including fruiting bodies and mycelia cultured on potato dextrose agar (PDA) plates and potato dextrose broth (PDB), respectively, and the GBMA has been revealed to exhibit the most significant antibacterial activity in our previous study (Abdullaha et al., 2020). LLE extraction shows improved extraction efficiency of secondary metabolites. This strategy for compound extraction implies that large amounts of polar substances can contribute to higher yields in more polar solvents (Seyd et al., 2012). While the obtained two fractions consist of water-methanol (WM) and chloroform-methanol (CM) fractions, the CM contain more potent antibacterial compounds. Thus, experiments using a combination of chloroform and methanol were used to obtain appropriate and ideal solubility strength in extracting the potent antibacterial secondary metabolites in this study. Compared to WM, the CM is estimated to be a more non-polar organic solvent. This characteristics of the combined solvent suggests that the antibacterial compounds may either be non-polar or slightly

polar in nature.

Based on this finding, we tried to isolate the antibacterial compounds in LLE fractions derived from G. boninense mycelia. For this, the pHPTLC separation and antibacterial bioautography were preferentially performed. The combined methods of pHPTLC and bioautography have been widely used to separate bioactive secondary metabolites. These compounds include polyphenols, flavonoids, saponins, alkaloids, and steroids (Annegowda et al., 2013), along with amino acids, proteins, peptides, hormones, and pesticides (Bhawani et al., 2012). With the help of using different UV wavelengths, TLC separation serves as a powerful tool for qualitative preliminary metabolite identification (Rajani et al., 2001). Based on these previous studies, fractionations using WM and CM were conducted with detection wavelengths of 254 and 366 $\mathrm{nm}$ through to the formation of separated bands (Fig. 1A and $B)$. A relatively weak inhibition band was observed in the band $(\mathrm{Rf}=0.4)$ against both MRSA and S. aureus. Non-significant visible bands were observed under visible light (white). No inhibition was also observed in other bacterial samples for the pHPTLC antibacterial bioautography (not shown). Our data are based on the fact that different properties between compounds are present in both fractions, as previously demonstrated by the different fluorescence profiles of mixed compounds (Marston and Hostettmann, 1999; Marston, 2007). However, the relatively lower fluorescence intensity observed in bands was presumably thought to be caused by low amounts of particular compounds (Rajani et al., 2001). Although TLC did not provide specific measurements, it can be very effective when used in combination with other techniques such as LC, GC, MS, FTIR, and NMR.

Antibacterial bioautography assays were performed to demonstrate the antibacterial properties of compounds separated via $\mathrm{pHPTLC}$ (Fig. $1 \mathrm{C}$ and $\mathrm{D}$ ). The soluble CM fraction displayed antibacterial activity $(\mathrm{Rf}=0.4)$ against MRSA NCTC 11939 and S. aureus ATCC 25923, whereas no inhibitory activity was observed against other pathogenic bacterial strains. Although there are several preparative strategies for isolating bioactive compounds, a major disadvantage in using TLC is

(A)

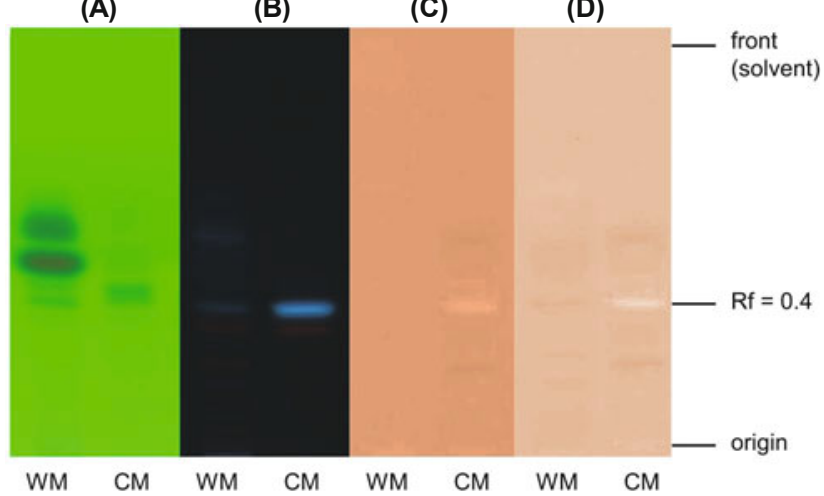

Fig. 1. The pHPTLC separation using a combination of fractions, including water-methanol (WM) and chloroform-methanol (CM). With a detection wavelength of (A) $254 \mathrm{~nm}$ and (B) $366 \mathrm{~nm}$, the result is visualized through pHPTLC antibacterial bioautography assay against pathogenic bacteria, including (C) MRSA (NCTC 11939) and (D) S. aureus (ATCC 25923). All experiments were repeated at least three times, independently. 
suggested to be its compounds-pooling power compared to other preparative chromatographic methods, mainly due to its relatively low retention capacity (Bucar et al., 2013). For example, the relatively weak activity of the CM fraction at $\mathrm{Rf}=0.4$ against two kinds of Gram-positive bacteria was due to a low amount of antibacterial compounds in the separated band. Nevertheless, owing to its greater resolution and separation capacity, TLC has been used to separate bioactive compounds from complex mixtures (Bucar et al., 2013). For further antibacterial compound isolation, the CM fraction ( $\mathrm{Rf}$ $=0.4$ ) was collected from 50 replicate plates so as to collect as many antibacterial compounds as possible. In addition, the $\mathrm{pHPTLC}$ of the CM fraction at $\mathrm{Rf}=0.4$ yielded $5 \mathrm{mg}$. Thus, isolated compounds from the pHPTLC of the CM fraction at $\mathrm{Rf}=0.4$ were designated as CMRF04.

\section{GC-MS identification of CMRF04}

Based on our data (Fig. 1), the methodological combination of using GC-MS with MS data processing software (i.e., MZmine and MassHunter) was used to achieve high-throughput and highly accurate experiments for compound identification (Misra et al., 2017). To enhance the efficiency of the isolation and identification processes for the possible antibacterial compounds, this present study employed combined experiments using GC-MS analysis. Three distinct peaks were observed and were designated as compounds $\mathrm{A}, \mathrm{B}$, and $\mathrm{C}$, and were correlated with their respective Rt (min). GC-MS values were also obtained and identified (Fig. 2). We identified two out of three possible antibacterial compounds from CMRF04 with the aid of NIST MS Search version 2.3 and NIST 17 EI Library Version. Compound A $(\mathrm{Rt}=28.78)$ was identified as $4,4,14 \alpha$-trimethylcholestane or lanostane $(\mathrm{m} / \mathrm{z}=414.75$, $\mathrm{C}_{30} \mathrm{H}_{54}$ ) with $94 \%$ identity (Supplementary data Fig. S1A), while compound B $(\mathrm{Rt}=29.17)$ was identified as ergosta- 5,7,22-trien-3 $\beta$-ol or ergosterol $\left(\mathrm{m} / \mathrm{z}=396.65, \mathrm{C}_{28} \mathrm{H}_{44} \mathrm{O}\right)$ with $99 \%$ identity (Supplementary data Fig. S1B). The described identity ratio (\%) was determined based on the $\mathrm{m} / \mathrm{z}$ fragmentation pattern when compared with the reference fragmentation pattern of similar compounds in the NIST 17 EI Library Version database. Both compounds are generally derived from triterpenes, which are essential to fungal lipid metabolism (Ríos and Andújar, 2017). Meanwhile, in the case of compound $\mathrm{C}(\mathrm{Rt}=29.89)$, the $\mathrm{m} / \mathrm{z}$ fragmentation pattern was successfully deduced from the MS data with mass and molecular formula (generated using MFG, MassHunter), which were revealed to be 498.66 and $\mathrm{C}_{30} \mathrm{H}_{42} \mathrm{O}_{6}$ (98.9\% accuracy based on MFG prediction), respectively (Supplementary data Fig. S1B). However, we failed to identify compound C using either the NIST MS Search version 2.3 or NIST 17 EI Library databases (Supplementary data Fig. S1C). Thus, a reliable identification for compound $\mathrm{C}$ based on its fragmentation pattern could not be obtained in this experiment.

\section{sPHPLC fractionation and spiking analysis on CMRF04}

Based on our earlier results (Fig. 2 and Supplementary data Fig. S1), we employed the sPHPLC method, which has been used as an excellent tool for separating and collecting particular compounds from a mixture due to its high sensitivity and isolation capacity (Marston and Hostettmann, 1999; Marston, 2007). In this study, sPHPLC (Snyder et al., 2012) was used to isolate a single component from a considerably complex mixture.

In this experiment, compounds $A$ and $B$ were spiked with their respective standard (A= lanostane, Sigma Aldrich; B = ergosterol, Sigma Aldrich) to validate the identities of peaks $A$ and B, respectively. Three distinctive peaks with their respective Rt were again observed in CMRF04, as indicated (Supplementary data Fig. S2). Three peaks were observed, and

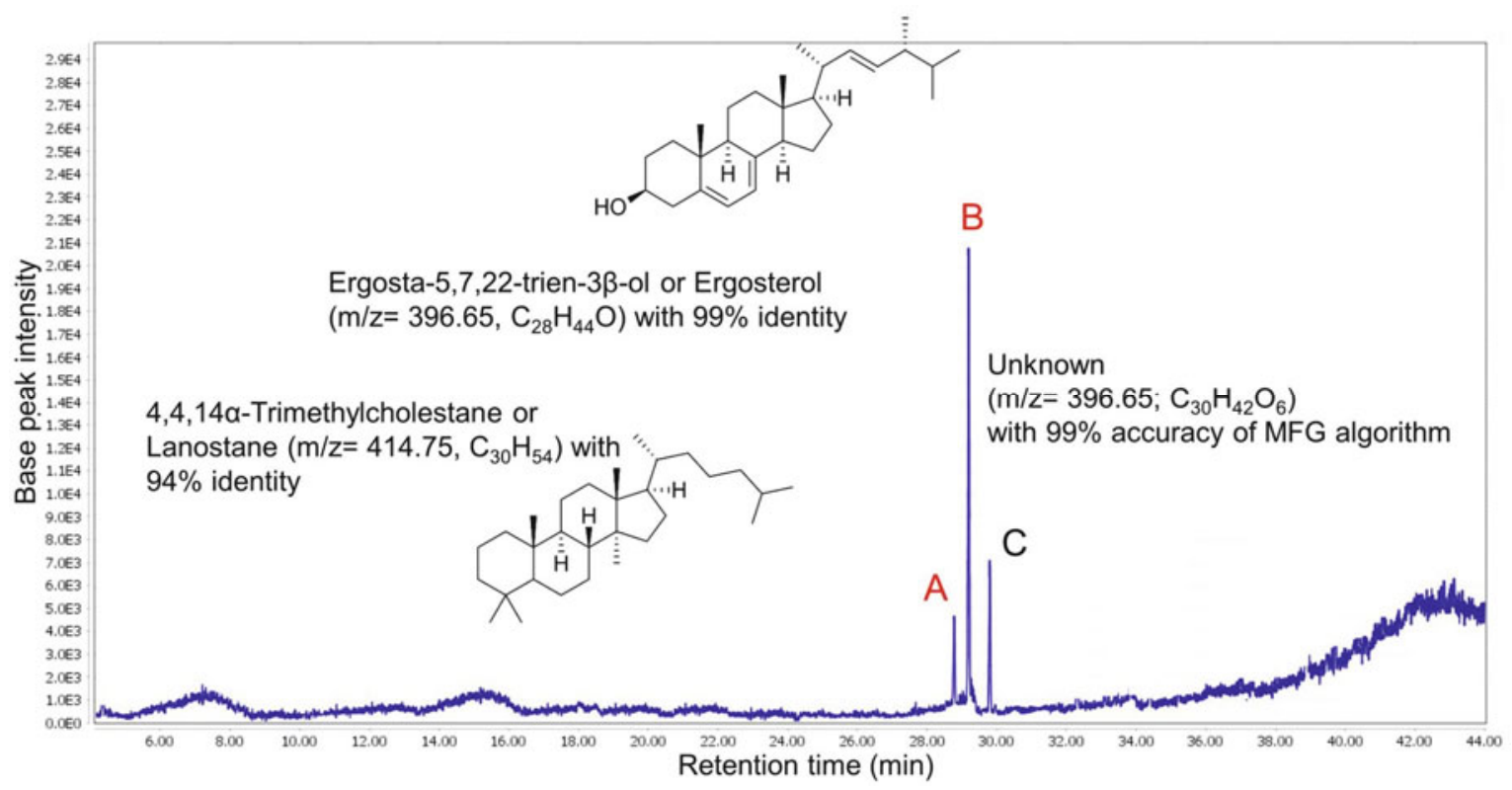

Fig. 2. The GC-MS chromatogram of each fraction separated by pHPTLC $(\mathrm{Rt}=\mathbf{0 . 4})$ from the CM fraction of $\mathbf{G}$. boninense extract. Three peaks, A, B, C, were observed and designated as compounds $\mathrm{A}(\mathrm{Rt}=28.78)$, compound $\mathrm{B}(\mathrm{Rt}=29.17)$, and compound $\mathrm{C}(\mathrm{Rt}=29.89)$, respectively. 
compounds A and B were spiked with their respective standards. Physically, $\mathrm{N}_{2}$-dried compound A was a yellowish oil, while compounds B and C were colorless and darker yellowish oils, respectively. As demonstrated by GC-MS analysis, compound A (red, Rt $=39.21$ ) and B (purple, Rt $=38.55)$ were characterized as lanostane and ergosterol, respectively. As the peaks corresponding to compounds $\mathrm{A}$ and $\mathrm{B}$ were positively spiked with their respective standards, they showed increases in the relative absorbance unit (mAU) at the same Rt without compromising chromatogram resolution. Because these were peaks formerly tested, compounds A and B were prominently determined in CMRF04; on the other hand, the third peak, compound C (green, Rt $=39.97$ ), remained unidentified. However, its molecular mass and formula were confirmed using GC-MS and MS data processing software. Experiments suggested that the observed different chromatogram profiles of CMRF04 between GC-MS and sPHPLC, in terms of compounds A, B, and C, originate from the column loaded and the GC-MS separation mechanisms which are mainly dependent on volatility and polarity (Marston and Hostettmann, 1999; Marston, 2007). This behavior explains why GC separation shows lanostane first, before showing ergosterol. Studies have suggested that the presence of hydroxyl groups in ergosterol affects the volatility of the compound by
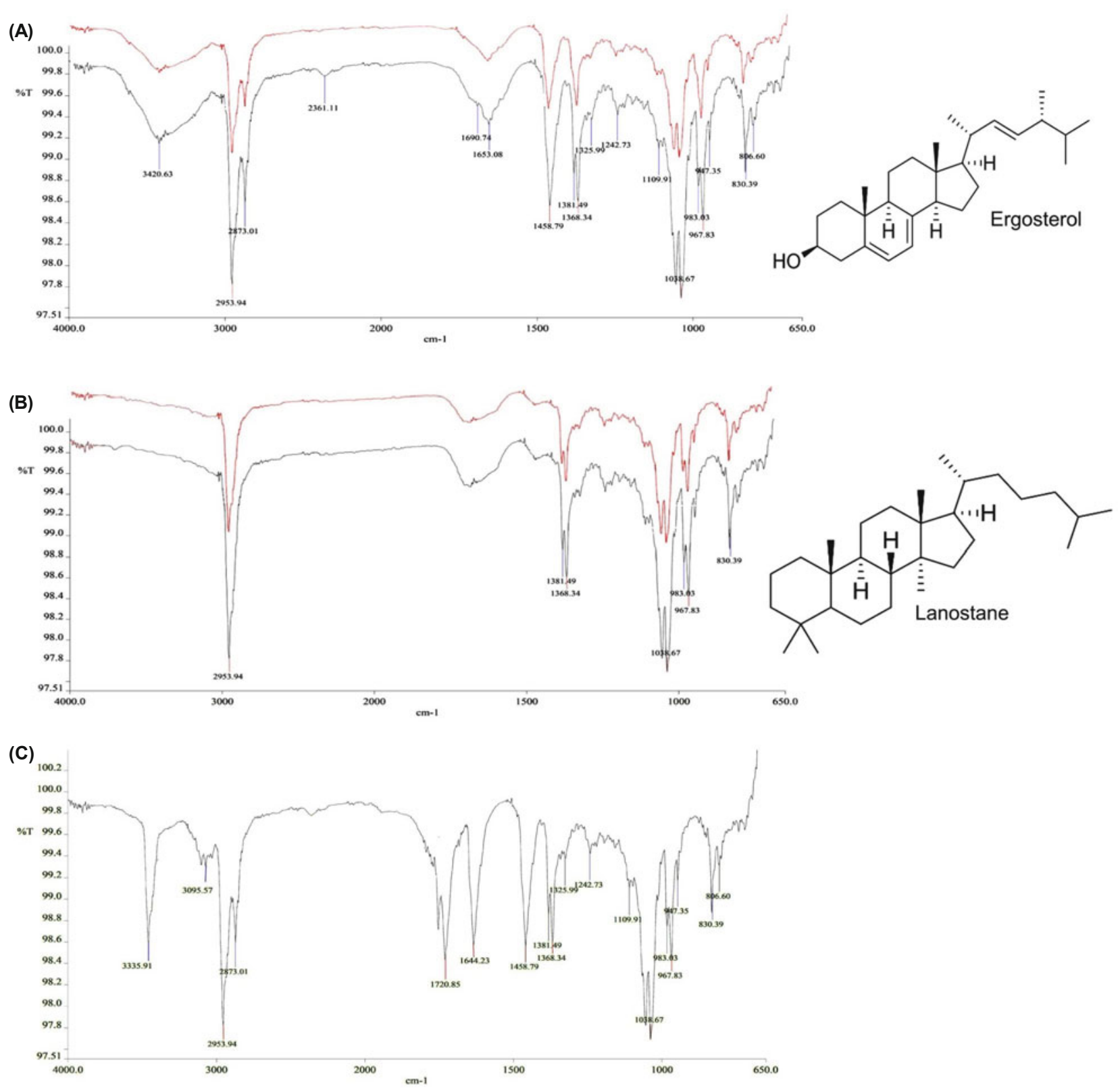

Fig. 3. FTIR spectroscopy analysis using the identified compounds A-C in this study. (A) FTIR spectroscopy analysis of compound A (black), along with standard lanostane (red). (B) FTIR spectroscopy of compound B (black) with standard ergosterol (red). (C) FTIR spectroscopy analysis of compound C. All experimental conditions are described in the 'Materials and Methods' section. The analysis shows the identical FTIR spectra between compound A and $\mathrm{B}$ and standards, lanostane and ergosterol. 
exerting a hydrogen bond effect, through an increase in the compound dipole moment (Bucar et al., 2013). Based on our results, we predicted that compound $\mathrm{C}$ has the lowest volatility and polarity compared to lanostane and ergosterol, causing it to elute last in both analyses.

\section{FTIR spectroscopy on compounds A, B, and C}

Utilization of IR spectroscopy for the identification of molecular structures commonly relies on the possibility of properly assigning absorption bands associated with their functional groups. Hence, most peaks and corresponding shoulders of the IR spectrum are attributable to specific functional groups (Bendini et al., 2007). With the aid of an already known compound and/or standard, identification of unknown compounds using IR and using additional information for related compounds have been made available in biological samples (Coates, 2006). Considering compounds A and B, these molecules were cross-referenced with lanostane and ergosterol, respectively. Figure 3 shows the matching FTIR spectra profiles for both compounds A and B with their respective standard, validating the identity of both compounds as lanostane and ergosterol, respectively. Therefore, lanostane and ergo- sterol standards will be used for further experimental studies of compounds A and B, respectively.

The FTIR spectra of compound C (Fig. 3C) displayed a spectroscopic profile with a variety of functional groups. A strong and sharp transmittance peak $(3,335.91 / \mathrm{cm})$ was observed, which is typically due to the presence of an alkyne terminal $(=\mathrm{C}-\mathrm{H})$. The presence of an $\mathrm{Sp}^{2}$ carbon, which has a trigonal planar structure, is commonly shown as a transmittance peak at the $3,100-3,000 / \mathrm{cm}$ region. At the observed FTIR spectrum of compound $\mathrm{C}$, in this region, successive small peaks indicated the presence of $\mathrm{Sp}^{2}$ carbons in this compound. Meanwhile, $\mathrm{Sp}^{3}$ carbons, which have tetrahedral structures, were detected in compound $\mathrm{C}$, indicated by the presence of transmittance peaks at $2,960-2,850 / \mathrm{cm}$. The strong band observed at $1,720.85 / \mathrm{cm}$ was due to the presence of a carbonyl group $(\mathrm{C}=\mathrm{O})$. A number of bands was observed at $1,242.73$, $1,109.91$, and $1,038.67 / \mathrm{cm}$, which are typically attributed to the presence of aliphatic ester or ether groups and C-O-C stretching. Bands at $1,458.79 / \mathrm{cm}$ and $1,381.49 / \mathrm{cm}$ were observed for $\mathrm{CH}_{3}$ and methyl symmetrical $\mathrm{C}-\mathrm{H}$, respectively. The peak observed at $1,644.23 / \mathrm{cm}$ suggested the presence of either a carbonyl group or amide moieties (Kavyanifard et al., 2016).

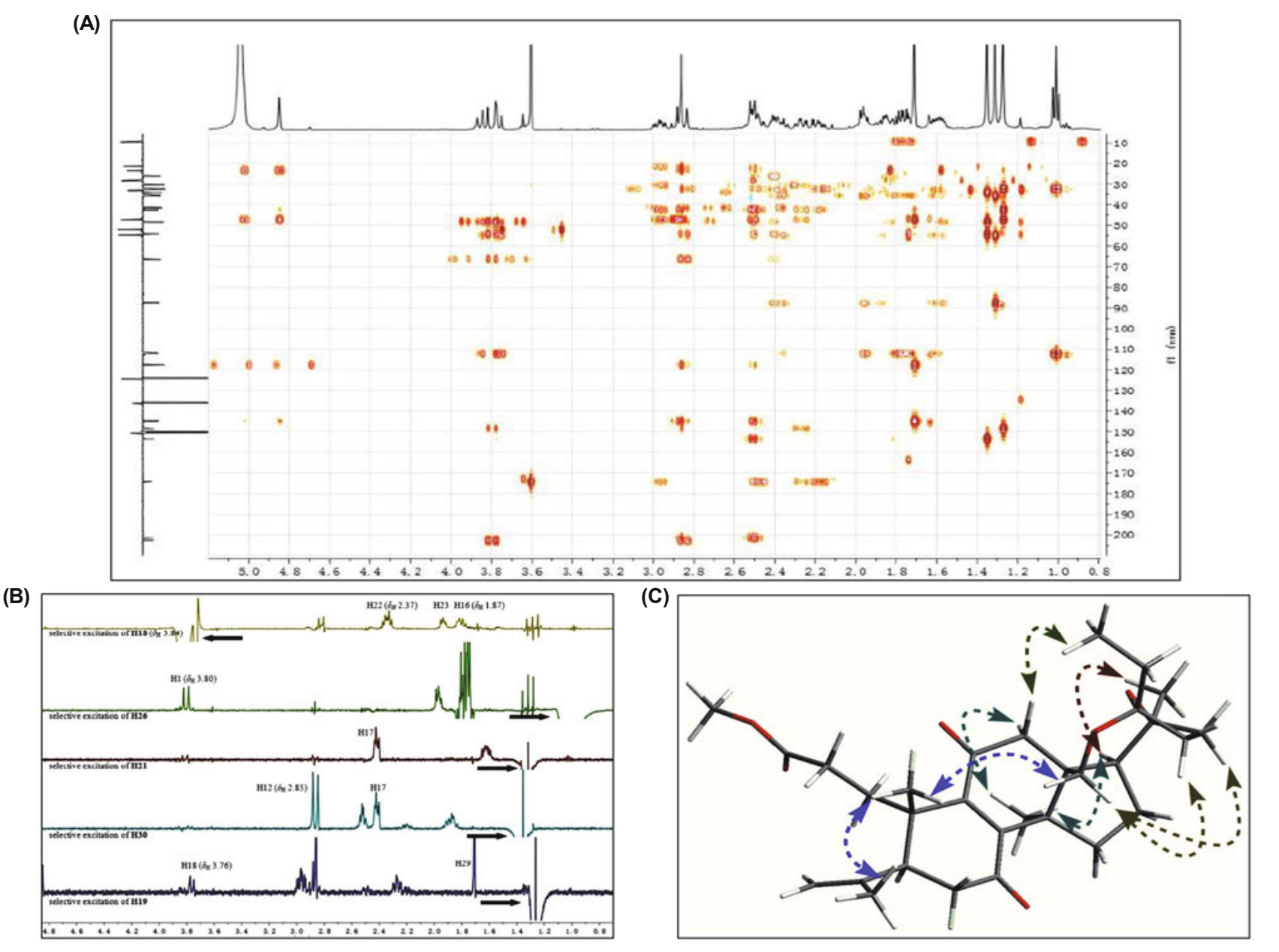

Fig. 4. The NMR spectroscopy for the structural confirmation of Ganoderma compound C. (A) HMBC spectrum of compound C in pyridine. (B) The NOESY excitation spectrums of compound $\mathrm{C}$ in pyridine $(500 \mathrm{MHz})$ and $(\mathrm{C})$ the planar structure of compound C deduced from NOESY spectrums in correlation with FTIR and HMBC data. 
Based on the FTIR results (Fig. 3), the structures of the newly isolated compounds can be supported through the identification of natural product compounds along with NMR spectroscopy (Marshall, 2013). In this experiment, the functional groups of compound $\mathrm{C}$ were determined using FTIR spectra. For example, the identified functional groups from compound $\mathrm{C}$ included an alkyne terminal, as well as the number of $\mathrm{Sp}^{2}$ (at least six of them) and $\mathrm{Sp}^{3}$ carbons (at least three of them), the number of aliphatic esters or ethers (at least three), and the number of carbonyl groups. The obtained data allowed us to elucidate the structure of compound $\mathrm{C}$ with respect to the NMR spectroscopy data.

\section{NMR spectroscopy for structural confirmation of compound C}

The molecular formula of compound $\mathrm{C}$ was established as $\mathrm{C}_{30} \mathrm{H}_{42} \mathrm{O}_{6}$ with 10 degrees of unsaturation. Herein, we performed NMR spectroscopy for the structural confirmation of compound $\mathrm{C}$ (Figs. 4 and 5). Analysis of the ${ }^{1} \mathrm{H}$ and ${ }^{13} \mathrm{C}$ NMR data for compound C (Supplementary data Table S3) revealed seven methyl groups (one methoxy), ten methylenes, (one oxymethylene), three methines (one oxymethine), five quaternary carbons including one doubly oxygenated Sp3 quaternary carbon $\left(\delta_{C} 112.1\right)$, four olefinic carbons including one terminal olefinic carbon, one carboxylic carbon $\left(\delta_{C}\right.$ 174.), and one carbonyl carbon $\left(\delta_{C} 202.7\right)$. Five isolated spin systems were established by ${ }^{1} \mathrm{H}-{ }^{1} \mathrm{H}$ COSY and HSQC correlations, as illustrated in Fig. 5A. In the HMBC spectrum of compound $\mathrm{C}$ (Figs. 4A and 5A), correlations of $\mathrm{H}-7 / \mathrm{C}-6$, C-8, C-9, and C-10, $\mathrm{H}_{3}-19 / \mathrm{C}-1, \mathrm{C}-5$, C-9, and C-10, $\mathrm{H}_{3}-29 /$ C-8, C-13, C-14, and C-15, and $\mathrm{H}_{2}-12 / \mathrm{C}-9, \mathrm{C}-11, \mathrm{C}-13$, $\mathrm{C}-14, \mathrm{C}-17$, and $\mathrm{C}-18$ furnished a 6-6-5 ring system. HMBC correlations from $\mathrm{H}-1$ to C-2, C-3, C-5, C-9, C-10, and C-19, with the correlation of $\mathrm{H}_{3}-30$ to $\mathrm{C}-3$ not only confirmed the presence of the methyl propionate moiety but also connected
C-1 with $\mathrm{C}-10$. HMBC correlations from $\mathrm{H}_{2}-27\left(\mathrm{H}_{3}-28\right)$ to C-4 and C-5 located the propenyl group at C-5, whereas $\mathrm{HMBC}$ correlations located the carbonyl group at C-7. Furthermore, HMBC correlations from $\mathrm{H}_{3}-21$ to C-17, C-20, and $\mathrm{C}-22$, and from $\mathrm{H}_{2}-25$ to C-23, C-24, and C-26 established the chain of C21-C26 (via C-20), with C-20 attached to $\mathrm{C}-17$. Finally, considering the chemical shifts of C-18 $\left(\delta_{C}\right.$ 66.4), C-20 $\left(\delta_{C} 87.60\right)$, and C-24 $\left(\delta_{C} 112.10\right)$, two C-24 bonded oxygen atoms were attached to C-18 and C-20, respectively to provide the complete structure and to satisfy the unsaturation requirement.

The relative configuration of compound $\mathrm{C}$ was established by NOE experiments (Figs. $4 \mathrm{~B}$ and $5 \mathrm{~A}$ ). NOEs from $\mathrm{H}_{3}-19$ to $\mathrm{H}-18\left(\delta_{H} 3.93\right), \mathrm{H}-28\left(\delta_{H} 4.82\right)$, and $\mathrm{H}_{3}-28$ indicated that these protons were on the same face of the 6-6-5 ring system, whereas NOEs of $\mathrm{H}-7$ with $\mathrm{H}-5$ and $\mathrm{H}_{3}-29$, and $\mathrm{H}_{3}-29$ with $\mathrm{H}-17$ and $\mathrm{H}-12\left(\delta_{H} 2.84\right)$ placed them on the opposite side of the rings. In addition, the NOEs of H-12 $\left(\delta_{H} 3.79\right)$ with $\mathrm{H}-18\left(\delta_{H} 3.93\right)$, and $\mathrm{H}_{3}-26$, and those of $\mathrm{H}-18\left(\delta_{H} 4.07\right)$ with $\mathrm{H}-22\left(\delta_{H} 2.43\right), \mathrm{H}_{2}-23$, and $\mathrm{H}-15\left(\delta_{H} 2.29\right)$ revealed their spatial proximity. Consequently, the relative stereochemistry of compound $\mathrm{C}$ was established as $5 S, 10 S, 13 S, 14 R, 17 S$, $20 S, 24 R$ (Fig. 5B). The absolute configuration of compound $\mathrm{C}$ was deduced by comparing the experimental and calculated ECD curves generated by the time-dependent density functional theory (TDDFT) (Fig. 5B). Considering the relative configuration determined above, one of the two isomers, $2 \mathrm{a}(5 S, 10 S, 13 S, 14 R, 17 S, 20 S, 24 R)$ or $2 \mathrm{~b}(5 R, 10 R, 13 R, 14 S$, $17 R, 20 R, 24 S)$, should represent the actual absolute configuration of compound C. A systematic conformational analysis was performed for $2 \mathrm{a}$ and $2 \mathrm{~b}$ using the molecular operating environment (MOE) software package and the MMFF94 molecular mechanics force field calculation. The MMFF94 conformational search followed by reoptimization using TDDFT obtained three lowest-energy conformers for enantiomers $2 \mathrm{a}$ and $2 \mathrm{~b}$, respectively (Table 1 ). The calculated ECD
(A)
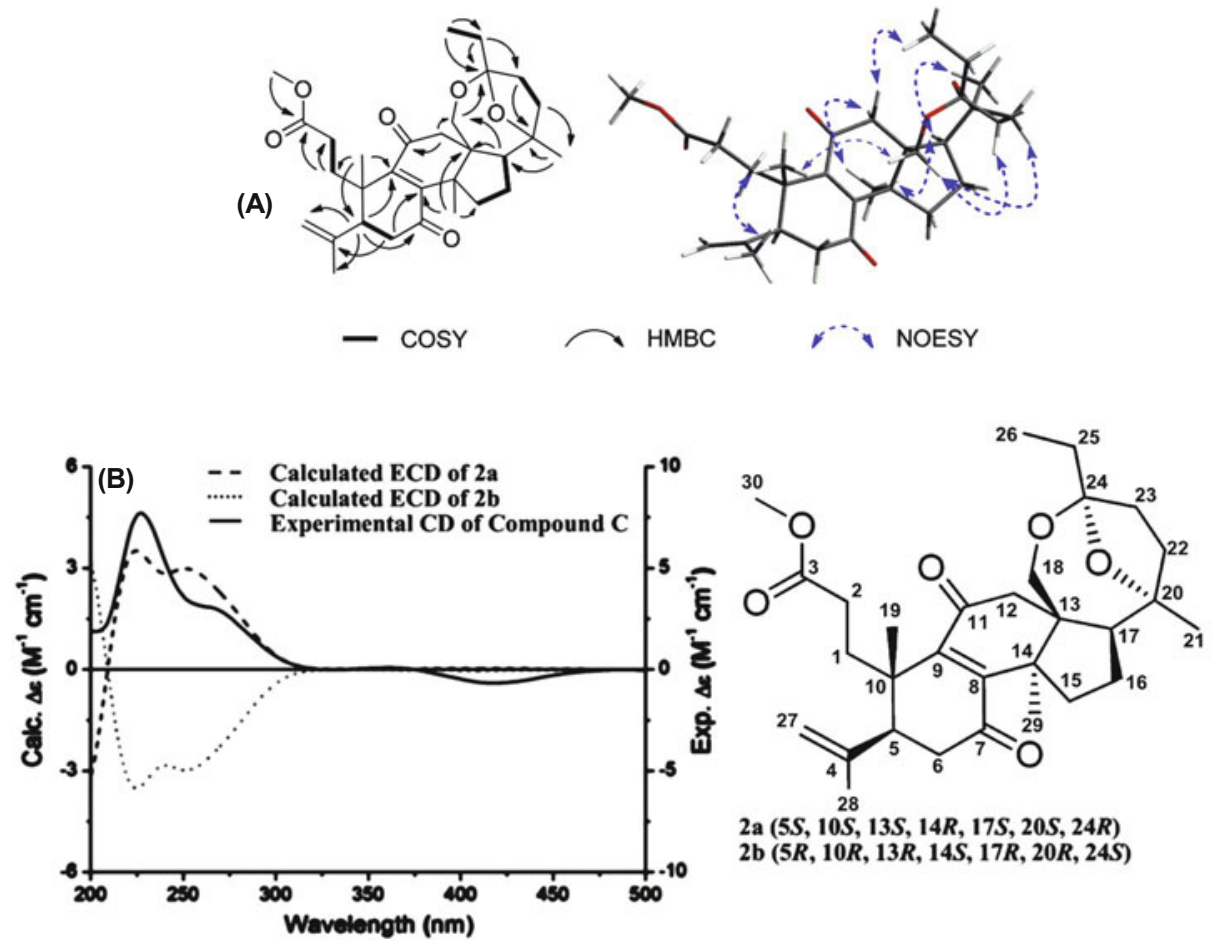

Fig. 5. Conformational analysis of compound $C$ by NMR spectroscopy and circular dichroism (CD). (A) COSY, HMBC, and NOESY correlations of compound C. The molecular models compound $\mathrm{C}$ in minimal energy were generated by Conflex calculations in silico using MMFF94's force field. (B) Experimental CD spectra of compound $\mathrm{C}$ in methanol and the calculated ECD spectra of $2 \mathrm{a}$ and $2 \mathrm{~b}$ with their respective configurations represent possible stereoisomers for compound C. 
Table 1. Final structure of compound C based on NMR spectroscopy with COSY, HMBC, NOESY, and ECD configuration analysis and their name according to IUPAC standard nomenclature

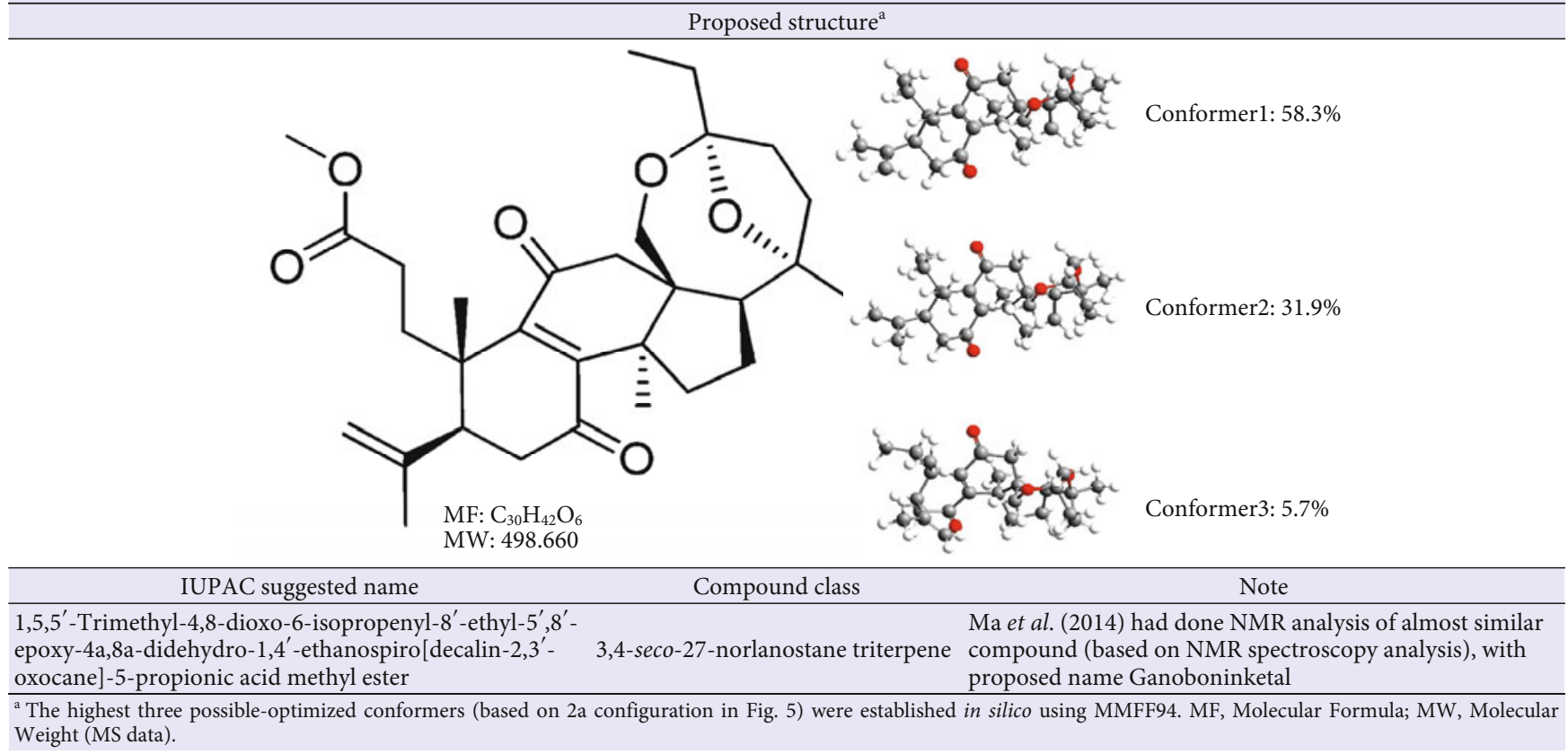

spectra were generated by a Boltzmann weighting of the conformers. Comparison of the experimental and calculated ECD curves of $2 \mathrm{a}$ and $2 \mathrm{~b}$ (Fig. $5 \mathrm{~B}$ ) allowed the unambiguous assignment of the absolute configuration of compound $\mathrm{C}$ as $5 S, 10 S, 13 S, 14 R, 17 S, 20 S, 24 R$. All of this data indicates that compound $\mathrm{C}$ belongs to the 3,4-seco-27-norlanostane triterpene group and the suggested IUPAC name is described in
Table 1.

In nature, 27-norlanostane triterpenes are rare. Examples include eight 27-norlanostane saponins from Muscari paradoxam and 14 and 10 norlanostane saponins from Scilla scilloides (Kuroda et al., 2004; Ono et al., 2012, 2013). Previously, Ma et al. (2014) isolated a similar compound with consider-

\section{Gram-positive bacteria}

Staphylococcus aureus ATCC 25923

Streptococcus pyogenes ATCC 19615

㯺 Methicillin-resistant Staphylococcus aureus NCTC 11939

Gram-negative bacteria

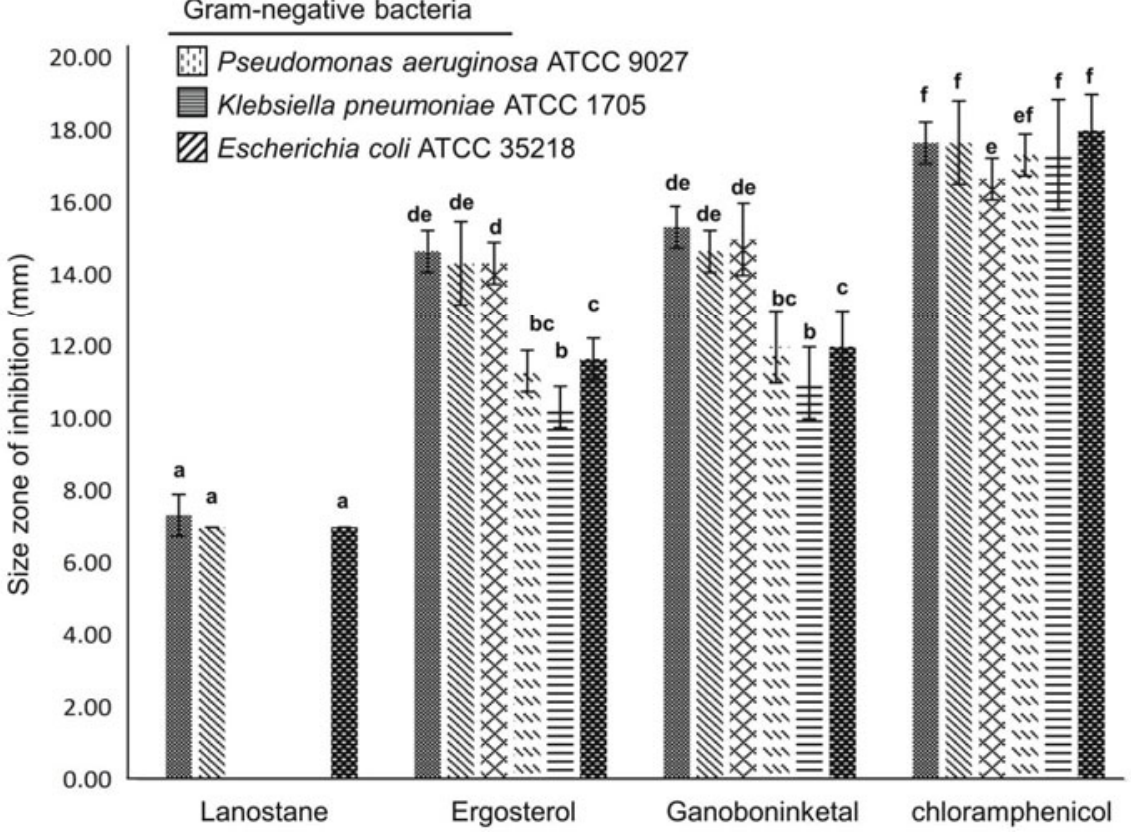

Fig. 6. Antibacterial activity of lanostane, ergosterol, and ganoboninketal against pathogenic bacteria. Bacterial strains were as follows: S. aureus ATCC 25923, S. pyogenes ATCC 19615, MRSA NCTC 11939, P. aeruginosa ATCC 9027, K. pneumoniae ATCC 1705, E. coli ATCC 35218. SA, S. aureus; SP, $S$. pyogenes; MRSA, methicillin-resistant $S$. aureus; PA, P. aeruginosa; KP, K. pneumoniae; EC, E. coli. Inhibition data denoted with different letters are significantly differ at $P$ $<0.05$. The error bar represents the standard deviation (SD) from the triplicates. No inhibition was observed on negative control discs (not shown). Data are expressed as means \pm standard deviation (SD) of at least three independent experiments. For each extract, mean values were significantly different at $P<0.05$ according to HSD Tukey's post hoc test. 
able anti-plasmodial activity and suggested ganoboninketal as the name of the compound. Ganoboninketals are new members of the 27-norlanostane triterpenes. We thereby hypothesize that ganoboninketal is produced as a secondary byproduct during lipid metabolism, especially in the squalene and sterol metabolisms of $G$. boninense (Ma et al., 2014, 2015). A possible biosynthetic pathway for ganoboninketal in this study has been proposed (Supplementary data Fig. S3). Accordingly, compound $\mathrm{C}$ is referred to as ganoboninketal throughout the remainder of this study.

\section{Antibacterial activities of lanostane, ergosterol, and gano- boninketal}

The identified compounds, including lanostane, ergosterol, and ganoboninketal, were evaluated for their antibacterial activity against the six bacterial samples. Both ergosterol and ganoboninketal displayed significant antibacterial activity compared to lanostane (Fig. 6), and exerted the most potent activity against $S$. aureus ATCC 25923 (ergosterol, $14.67 \pm 0.33$ $\mathrm{mm}$; ganoboninketal $15.33 \pm 0.58 \mathrm{~mm}), S$. pyogenes ATCC 19615 (ergosterol, $14.33 \pm 1.15 \mathrm{~mm}$; ganoboninketal, $14.67 \pm$ $0.58 \mathrm{~mm}$ ), and MRSA and NCTC 11939 (ergosterol, $14.33 \pm$ $0.58 \mathrm{~mm}$; ganoboninketal $15.00 \pm 1.00 \mathrm{~mm}$ ). Meanwhile, both ergosterol and ganoboninketal showed significantly lower antibacterial activity against Gram-negative bacteria. The lowest activity was observed against K. pneumoniae ATCC 1705 (ergosterol, $10.33 \pm 0.58 \mathrm{~mm}$; ganoboninketal, $11.00 \pm 1.00 \mathrm{~mm}$ ), although it was not significantly lower than that of $P$. aeruginosa ATCC 9027 (ergosterol, $11.33 \pm 0.58 \mathrm{~mm}$; ganoboninketal, $12.00 \pm 1.00 \mathrm{~mm}$ ). Arrangement of carbon-harboring pi electrons, hydroxyl groups, and carbonyl groups contributed to their hydrophobicity and lipophilic characteristics, which play important roles in inducing the antibacterial effect of a particular compound (Ben Arfa et al., 2006). Carboxyl, hydroxyl, and carbonyl groups are essential for antibacterial activity because they mediate binding to the DNA-gyrase complex through hydrogen bonds or through electron disruptive formation (Tomašic et al., 2015). The groups were also able to induce chelating ability, which is an essential requirement for transport into bacterial cells (Cui et al., 2016). In this case, ergosterol contains one hydroxyl group at carbon number three while ganoboninketal contains several carbonyl groups. Substantive aliphatic structures (both saturated and unsaturated) in a compound induce the compound's hydrophobicity, thus assisting its ability to insert itself into bacterial cell membranes (Desbois and Smith, 2010). Hydrophobic compounds are generally reported to be most toxic to cytoplasmic membranes, as they often disrupt and disintegrate membrane structures (Ben Arfa et al., 2006). With these in mind, two hypotheses were made on ergosterol and ganoboninketal: 1) both compounds induce antibacterial effects through bacterial membrane disintegration, and 2) both compounds easily penetrate bacterial cell barriers with the aid of hydrophobic regions. Thus, the antibacterial effect was exerted by the hydroxyl or carbonyl group through metabolic or molecular inhibition.

In the case of lanostane, although the compound possesses great hydrophobicity due to the presence of a substantive hydrocarbon structure, its antibacterial activity was least observed. This phenomenon is best explained in non-disrup- tive hydrophobic compounds towards bacterial membrane cells (Sikkema et al., 1995). The hydrophobic region enables a particular compound to insert itself into bacterial cell membranes, but cannot disrupt the membrane cells' structure because its own structure is not massive enough (Sikkema et al., 1995). Nonetheless, a hydrophobic disruptive effect by lanostane was observed in S. aureus ATCC 25923, S. pyogenes ATCC 19615, and E. coli ATCC 35218, but this effect was very minimal.

\section{Acknowledgments}

This research was supported by the Ministry of Education of Malaysia (FRGS0384-SG-2/2014). Syahriel Abdullah and Yoon Sin Oh-Two contributed equally to this work and should be considered co-first authors.

\section{Conflict of Interest}

The authors declare that there are no competing interests associated with the manuscript.

\section{References}

Abdullah, S., Jang, S.E., Kwak, M.K., and Chong, K.P. 2020. Ganoderma boninense mycelia for phytochemicals and secondary metabolites with antibacterial activity. J. Microbiol. 58, 1054-1064.

Abdullah, S., Soon, L.Y., Daim, S.J., and Chong, K.P. 2018. Isolation and characterization of antibacterial compounds from Ganoderma boninense against methicillin-resistant Staphylococcus aureus (MRSA). Borneo J. Med. Sci. 1, 11-12.

Anke, T. 1989. Basidiomycetes: a source for new bioactive secondary metabolites. Prog. Ind. Microbiol. 27, 51-66.

Annegowda, H.V., Tan, P.Y., Mordi, M.N., Ramanathan, S., Hamdan, M.R., Sulaiman, M.H., and Mansor, S.M. 2013. TLC-bioautography-guided isolation, HPTLC and GC-MS-assisted analysis of bioactives of Piper betle leaf extract obtained from various extraction techniques: in vitro evaluation of phenolic content, antioxidant and antimicrobial activities. Food Anal. Methods 6, 715-726.

Ben Arfa, A., Combes, S., Preziosi-Belloy, L., Gontard, N., and Chalier, P. 2006. Antimicrobial activity of carvacrol related to its chemical structure. Lett. Appl. Microbiol. 43, 149-154.

Bendini, A., Cerretani, L., Di Virgilio, F., Belloni, P., Bonoli-Carbognin, M., and Lercker, G. 2007. Preliminary evaluation of the application of the FTIR spectroscopy to control the geographic origin and quality of virgin olive oils. J. Food Qual. 30, 424-437.

Bhawani, S.A., Mohamad Ibrahim, M.N., Sulaiman, O., Hashim, R., Mohammad, A., and Hena, S. 2012. Thin-layer chromatography of amino acids: a review. J. Liq. Chromatogr. Relat. Technol. 35, 1497-1516.

Brannan, D.K. 2006. Biology of microbes. In Geis, P.A. (ed.), Cosmetic Microbiology: A Practical Approach. 2nd edn. pp. 19-69. Taylor \& Francis, New York, USA.

Bucar, F., Wube, A., and Schmid, M. 2013. Natural product isolation-how to get from biological material to pure compounds. Nat. Prod. Rep. 30, 525-545.

Chong, K.P., Abdullah, S., and Tong-Leong, N. 2013. Molecular fingerprint of Ganoderma spp. from Sabah, Malaysia. Int. J. Agric. Biol. 15, 1112-1118.

Chong, K.P., Atong, M., and Rossall, S. 2012. The role of syringic acid 
in the interaction between oil palm and Ganoderma boninense, the causal agent of basal stem rot. Plant Pathol. 61, 953-963.

Chong, K.P., Eldaa, P.A., and Dayou, J. 2014. Relation of Ganoderma ergosterol content to Basal Stem Rot disease severity index. $A d v$. Environ. Biol. 8, 14-19.

Chong, K.P., Rossall, S., and Atong, M. 2011. HPLC Fingerprints and in vitro antimicrobial activity of syringic acid, caffeic acid and 4-hydroxybenzoic acid against Ganoderma boninense. J. Appl. Sci. 11, 2284-2291.

CLSI, Clinical Laboratory Standards Institute. 2011. Performance standards for antimicrobial susceptibility testing; 21st informational supplement. CLSI document M100-S21. Clinical Laboratory Standards Institute, Wayne, Pennsylvania, USA.

Coates, J. 2006. Interpretation of infrared spectra, a practical approach. In Meyers, R.A. and McKelvy, M.L.(eds.), Encyclopedia of analytical chemistry: applications, theory and instrumentation. John Wiley \& Sons, Inc., Hoboken, New Jersey, USA. https://doi. org/10.1002/9780470027318.a5606.

Corley, R., Hereward, V., and Tinker, P.B. 2008. The oil palm. John Wiley \& Sons, Hoboken, New Jersey, USA.

Cui, S.F., Addla, D., and Zhou, C.H. 2016. Novel 3-aminothiazolquinolones: design, synthesis, bioactive evaluation, SARs, and preliminary antibacterial mechanism. J. Med. Chem. 59, 44884510.

Daruliza, K.M.A., Fernandez, L., Jegathambigai, R., and Sasidharan, S. 2012. Anti-Candida activity and brine shrimp toxicity assay of Ganoderma boninense. Eur. Rev. Med. Pharmacol. Sci. 16, 43-48.

Desbois, A.P. and Smith, V.J. 2010. Antibacterial free fatty acids: activities, mechanisms of action and biotechnological potential. Appl. Microbiol. Biotechnol. 85, 1629-1642.

Gong, T., Yan, R., Kang, J., and Chen, R. 2019. Chemical components of Ganoderma. In Lin, Z. and Yang, B. (eds.), Ganoderma and Health, pp. 59-106. Springer, Singapore.

Ho, Y.W. and Nawawi, A. 1985. Ganoderma boninense Pat. from based stem rot of oil palm [Elaeis guineensis] in Peninsular Malaysia. Pertanika 8, 425-428.

Ismail, K., Abdullah, S., and Chong, K.P. 2014. Screening for potential antimicrobial compounds from Ganoderma boninense against selected food borne and skin disease pathogens. Int. J. Pharm. Pharm. Sci. 6, 771-774.

Kavyanifard, A., Ebrahimipour, G., and Ghasempour, A. 2016. Structure characterization of a methylated ester biosurfactant produced by a newly isolated Dietzia cinnamea $\mathrm{KA}_{1}$. Microbiology 85, 430-435.

Kuroda, M., Mimaki, Y., Ori, K., Sakagami, H., and Sashida, Y. 2004. Steroidal glycosides from the bulbs of Ornithogalum thyrsoides. J. Nat. Prod. 67, 1690-1696.

Ma, K., Li, L., Bao, L., He, L., Sun, C., Zhou, B., Si, S., and Liu, H. 2015. Six new 3, 4-seco-27-norlanostane triterpenes from the medicinal mushroom Ganoderma boninense and their antiplasmodial activity and agonistic activity to LXR $\beta$. Tetrahedron 71, 1808814.

Ma, K., Ren, J., Han, J., Bao, L., Li, L., Yao, Y., Sun, C., Zhou, B., and Liu, H. 2014. Ganoboninketals A-C, antiplasmodial 3, 4-seco-27norlanostane triterpenes from Ganoderma boninense pat. J. Nat. Prod. 77, 1847-1852.

Mahrous, E.A. and Farag, M.A. 2015. Two dimensional NMR spectroscopic approaches for exploring plant metabolome: a review. J. Adv. Res. 6, 3-15.

Marshall, A. 2013. Fourier, hadamard, and hilbert transforms in chemistry. Springer Science+Business Media, New York, USA.

Marston, A. 2007. Role of advances in chromatographic techniques in phytochemistry. Phytochemistry 68, 2786-2798.

Marston, A. and Hostettmann, K. 1999. Biological and chemical evaluation of plant extracts and subsequent isolation strategy. In Bohlin, L. and Bruhn, J.G. (eds.), Bioassay Methods in Natural Product Research and Drug Development. Proceedings of the
Phytochemical Society of Europe. vol. 43, pp. 67-80. Springer, Dordrecht, Germany.

Misra, B.B., Fahrmann, J.F., and Grapov, D. 2017. Review of emerging metabolomic tools and resources: 2015-2016. Electrophoresis 38, 2257-2274.

Molinski, T.F. 2010. NMR of natural products at the 'nanomole-scale'. Nat. Prod. Rep. 27, 321-329.

Ofodile, L.N., Uma, N., Grayer, R.J., Ogundipe, O.T., and Simmonds, M.S.J. 2012. Antibacterial compounds from the mushroom $\mathrm{Ga}$ noderma colossum from Nigeria. Phytother. Res. 26, 748-751.

Ono, M., Ochiai, T., Yasuda, S., Nishida, Y., Tanaka, T., Okawa, M., Kinjo, J., Yoshimitsu, H., and Nohara, T. 2013. Five new nortriterpenoid glycosides from the bulbs of Scilla scilloides. Chem. Pharm. Bull. 61, 592-598.

Ono, M., Takatsu, Y., Ochiai, T., Yasuda, S., Nishida, Y., Tanaka, T., Okawa, M., Kinjo, J., Yoshimitsu, H., and Nohara, T. 2012. Two new nortriterpenoid glycosides and a new phenylpropanoid glycoside from the bulbs of Scilla scilloides. Chem. Pharm. Bull. 60, 1314-1319.

Peng, X.R., Liu, J.Q., Wang, C.F., Li, X.Y., Shu, Y., Zhou, L., and Qiu, M.H. 2014. Hepatoprotective effects of triterpenoids from Ganoderma cochlear. J. Nat. Prod. 77, 737-743.

Rajani, M., Ravishankara, M.N., Shrivastava, N., and Padh, H. 2001. HPTLC-aided phytochemical fingerprinting analysis as a tool for evaluation of herbal drugs. A case study of Ushaq (ammoniacum gum). JPC-J. Planar Chromat. 14, 34-41.

Rajauria, G. and Abu-Ghannam, N. 2013. Isolation and partial characterization of bioactive fucoxanthin from Himanthalia elongata brown seaweed: a TLC-based approach. Int. J. Anal. Chem. 2013, 802573.

Richter, C., Wittstein, K., Kirk, P.M., and Stadler, M. 2015. An assessment of the taxonomy and chemotaxonomy of Ganoderma. Fungal Divers. 71, 1-15.

Ríos, J.L. and Andújar, I. 2017. Lanostanoids from fungi as potential medicinal agents. In Mérillon, J.M. and Ramawat, K. (eds), Fungal Metabolites, pp. 1-34. Springer, Cham, New York, USA.

Sarker, S.D. and Nahar, L. 2012. An introduction to natural products isolation. Methods Mol. Biol. 864, 1-25.

Schlotterbeck, G. and Ceccarelli, S.M. 2009. LC-SPE-NMR-MS: a total analysis system for bioanalysis. Bioanalysis 1, 549-559.

Schwan, W.R. 2012. Mushrooms: an untapped reservoir for nutraceutical antibacterial applications and antibacterial compounds. Curr. Top. Nutraceutical. Res. 10, 75-82.

Seyd, A.H., Lanez, T., and Belfar, M.L. 2012. Modelling of yield and distribution coefficient in a liquid-liquid extraction: Effect of the concentration of ligand. Asian J. Chem. 24, 4511-4516.

Sikkema, J., De Bont, J.A., and Poolman, B. 1995. Mechanisms of membrane toxicity of hydrocarbons. Microbiol. Rev. 59, 201-222.

Snyder, L.R., Kirkland, J.J., and Glajch, J.L. 2012. Practical HPLC method development. 2nd edn., John Wiley \& Sons, Inc., Hoboken, New Jersey, USA.

Tomašǐc, T., Katsamakas, S., Hodnik, Ž., Ilaš, J., Brvar, M., Solmajer, T., Montalvão, S., Tammela, P., Banjanac, M., Ergović, G., et al. 2015. Discovery of 4, 5, 6, 7-tetrahydrobenzo $[1,2-d]$ thiazoles as novel DNA gyrase inhibitors targeting the ATP-binding site. J. Med. Chem. 58, 5501-5521.

Valle, D.L., Puzon, J.J.M., Cabrera, E.C., and Rivera, W.L. 2016. Thin layer chromatography-bioautography and gas chromatographymass spectrometry of antimicrobial leaf extracts from Philippine Piper betle L. against multidrug-resistant bacteria. Evid. Based Complement. Alternat. Med. 2016, 4976791.

Vetter, I., Davis, J.L., Rash, L.D., Anangi, R., Mobli, M., Alewood, P.F., Lewis, R.J., and King, G.F. 2011. Venomics: a new paradigm for natural products-based drug discovery. Amino Acids 40, $15-28$. 